\title{
CONTROL AND FAULT DIAGNOSIS BASED SLIDING MODE OBSERVER OF A MULTICELLULAR CONVERTER: HYBRID APPROACH
}

\author{
Omar Benzineb $^{*}$ - Fateh Taibi ${ }^{* * *}$ — Taous Meriem Laleg-Kirati ${ }^{* *}$ \\ Mohamed Seghir Boucherit ${ }^{* * *}$ — Mohamed Tadjine ${ }^{* * *}$
}

\begin{abstract}
In this article, the diagnosis of a three cell converter is developed. The hybrid nature of the system represented by the presence of continuous and discrete dynamics is taken into account in the control design. The idea is based on using a hybrid control and an observer-type sliding mode to generate residuals from the observation errors of the system. The simulation results are presented at the end to illustrate the performance of the proposed approach.

K e y w o r d s: multicellular converter, diagnosis based-observer, hybrid observer, residual, cell fault sliding mode, hybrid dynamical systems
\end{abstract}

\section{INTRODUCTION}

Hybrid systems represent a multidisciplinary area which has been developed over the past decade and extends between the limits of computer science, control theory and mathematics. A hybrid system is a mathematical model capable of representing some complex physical systems with a hierarchical structure and consists of discrete and continuous sub - systems that communicate and interact with each other. Switching circuits in power electronics are considered as a good application for hybrid analysis, because they are intrinsically hybrid in their structures. Under this hybrid model, the system has discrete inputs, continuous outputs, and disturbances that are either continuous, such as parametric variation in a load or source, or discrete, as in a fault state of a particular switch. Among these switching circuits, there are the multicellular converters that are based on the series connection of elementary switching cells. This structure has emerged in the early 90 [5-7], it is possible to share the constraints in tension and/or current when functioning in high- voltage installation by switching connected cells in series and also to improve the harmonic content of the waveforms.

These converters have two major advantages: first, the distribution of voltage and current constraints under high powers and the second are the spectral qualities that present the output voltage.

Besides, the modeling is a very important phase for the synthesis of control laws and observers [6]. The accuracy of the model depends on the required objectives. For this reason, we can find several types of models for the same process and the choice among these models depends on its using and the purpose of control. For the synthesis of the control or observer, the chosen model must be simple enough to allow the realization of real-time control (or observer), but it must be precise enough to get the desired behavior [8]. To benefice the most enormous potential of the multicellular structure, the research is oriented in different directions. The modeling of multicellular converters is generally difficult. Indeed, it contains continuous variables (voltages and currents) and discrete variables (switches, or a discreet location) [1].

In the literature, there are three main types of models [3]: - An average model whose principle is based on calculating average value of all the variables over one sampling period. This model cannot represent the natural balancing of the terminal voltages of the capacities. Indeed, natural balancing is due to the harmonics of the charging current at the cutting frequency. - The second model takes into account of the harmonics, and is called for this fact harmonic model. It is based on the determination of the phases and amplitudes of the voltages harmonics by considering the charging current in steady operation. - The third model is the exact or instantaneous model which takes into account the evolution at every moment of all the variables including the state of the switch (discrete location). This model is difficult to use for the design of controllers and observers based on; it is impossible since the converter is not continuous system but a combination of continuous/discrete systems [2-4]. Hybrid modelling allows multicellular converter to use powerful tools of analysis and synthesis for better exploration of the possibilities of the controllers [9].

The diagnosis process at the beginning was manual but with the advancement of digital computers, it became

\footnotetext{
* University of Blida, Laboratory LABSET, Route de Soumma, Blida, Algeria; ${ }^{* *}$ Kaust University, Applied Mathematics and Computer Sciences Division, Saudi Arabia, ${ }^{* * *}$ Ecole Nationale Polytechnique, ENP. 10, Avenue Hassen Badi, BP 182, 16200 El-Harrach, Algeria
} 


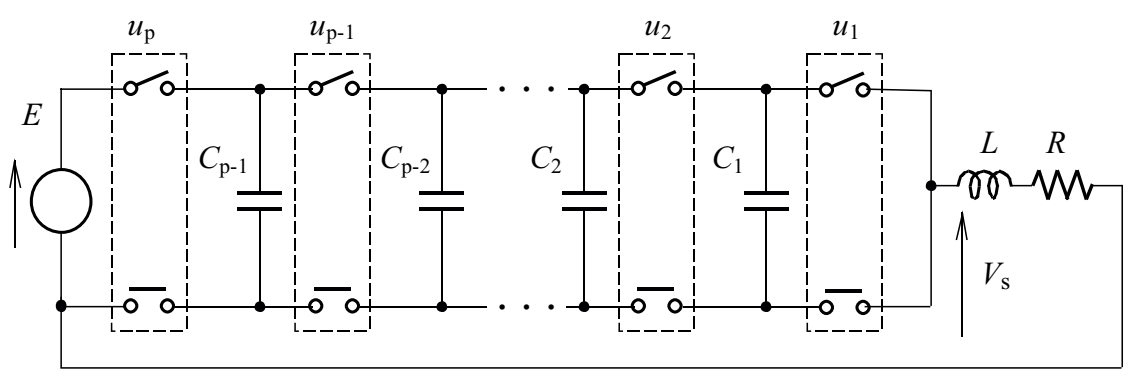

Fig. 1. $p$-cell converter

automatic and it has evolved as well as all the areas of control discipline. The research works on diagnosis basedmodel have been intensified in the 80's and 90's. Today, it is still a growing research area with many unresolved issues. The diagnosis can be designed for the supervising of industrial processes in order to alarm the staff working in these installations that there is a dysfunction of the process which must provoke an urgent intervention or even stop the total process. We find the diagnosis systems especially in chemical or nuclear processes that represent potential risks in terms of safety and the environment. There are other processes that are not limited by this supervision function, but they can be used for control. We are talking about fault tolerant control that can be adapted with the presence of failure mode when a fault occurs in the system.

In this article, the diagnosis based-observer is proposed. The method pursued is developed using hybrid sliding mode observer which represents a witness in the system and gives information on the occurrence or not of a fault type cell. We begin by modeling the multicellular structure by an automata to deal with the hybrid nature of this system and then we synthesize a sliding mode observer. Furthermore, a residual generation and evaluation block is proposed. Then we attack the diagnosis phase by illustrating the used approach. At the end, simulations are presented to highlight the advantages of our approach.

\section{MULTICELLULAR CONVERTERS MODELLING AND HYBRID AUTOMATA}

\subsection{Multicellular Converter}

As said before, there three types of modeling that can be used to represent the model of multicellular converters. The first is the average model. Under this model, the switching action is replaced by the average of the switched amount, and the switching duty cycle becomes a gain varying between 0 and 1 . The switching frequency does not appear in this analysis, and the trajectories of the system have continuous first order derivatives. The model is not necessarily linear, in fact, taking the continuous duty cycle as input can be often translated by a multiplicative term in the state space representation. This model cannot represent the natural balancing of the terminal voltages of the capacities. Indeed, natural balancing is due to the harmonics of the charging current at the cutting frequency. Another approach is to develop a discrete time or sampled data model. Once again, the switching frequency does not appear explicitly in the analysis. As with averaging methods, discretization does not necessarily result in a linear model. Clearly, the models obtained with such methods are limited in their ability to describe the system dynamics. Circuit behaviour between switching instances is lost, and the ability to predict important nonlinear behaviours is lost. The second model is the harmonic model based on the decomposition in Fourier series of control signals. It allows obtaining a dynamic representation of multicellular converter taking into account of harmonic phenomena. The third model is the exact or instantaneous model which takes into account the evolution at every moment of all the variables including the state of the switch (discrete location). From this fact, all the average or harmonic phenomena are taken into account in this model. However, this model cannot be used directly for control or observation purposes since the dimension of the state space model describing the instantaneous behaviour varies with the state of the switches leading to several continuous state space models representing the converter and at each time the converter can be represented by one of these continuous models. Hence, a Hybrid model is used to represent exactly the converter.

The multicellular converter consists of cells. Each cell contains two complementary power electronics components and it can be controlled by a binary switch $u_{k}$. This signal $u_{k}$ is equal to 1 when the upper switch of the cell is conducting and 0 when the lower complementary switch of the cell is conducting. These cells are associated in series with $R, L$ load and separated by capacities that can be considered as continuous sources to these cells.

The converter has $p-1$ floating voltage sources. In order to ensure a normal functioning, it is necessary to guaranty a regulated distribution of the voltages $V c_{k}$ to their equilibrium values that equal to $k E / p$ [10].

The output voltage $V s$ possesses $p$ voltage levels $\left(0, \frac{E}{p}, \ldots, \frac{(p-1) E}{p}, E\right)$. The model of this system can be obtained and represented by $p$ differential equations giving its state space representation with floating voltages 


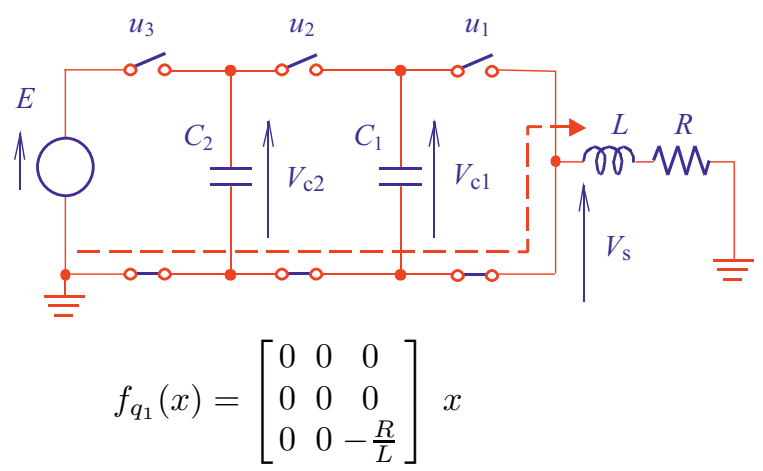

Fig. 2. Mode $q_{1},\left(u_{3}=0, u_{2}=0, u_{1}=0\right)$

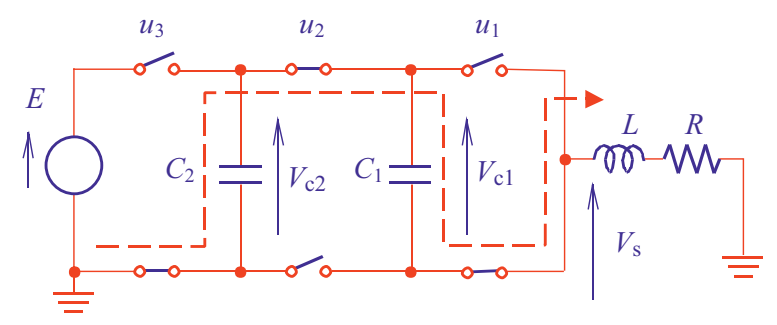

$$
f_{q_{1}}(x)=\left[\begin{array}{ccc}
0 & 0 & 1 / C_{1} \\
0 & 0 & -1^{\prime} C_{1} \\
-1 / L & 1 / L & -R / L
\end{array}\right] x
$$

Fig. 4. Mode $q_{1},\left(u_{3}=0, u_{2}=0, u_{1}=0\right)$

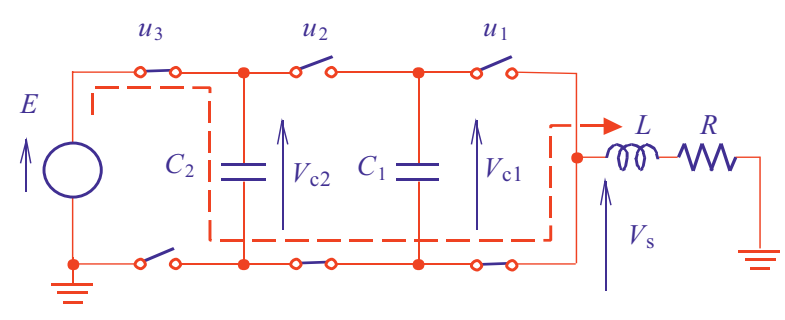

$$
f_{q_{1}}(x)=\left[\begin{array}{ccc}
0 & 0 & 0 \\
0 & 0 & 1 / C_{2} \\
0 & -1 / L & -R / L
\end{array}\right] x+\left[\begin{array}{c}
0 \\
0 \\
E / L
\end{array}\right]
$$

Fig. 6. Mode $q_{1},\left(u_{3}=0, u_{2}=0, u_{1}=0\right)$

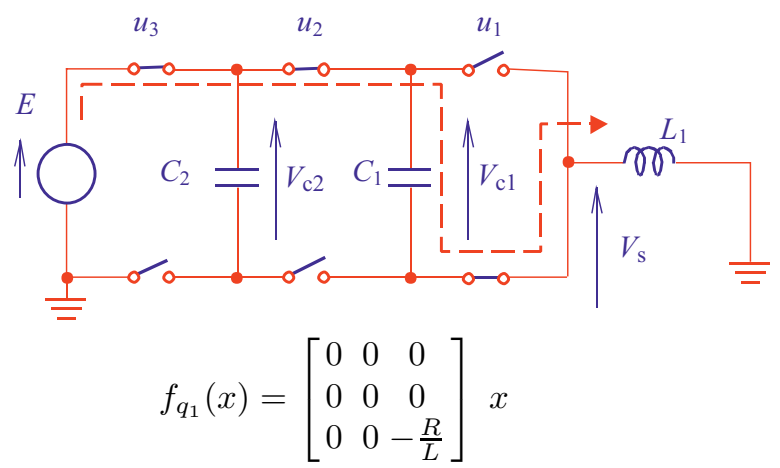

Fig. 8. Mode $q_{1},\left(u_{3}=0, u_{2}=0, u_{1}=0\right)$

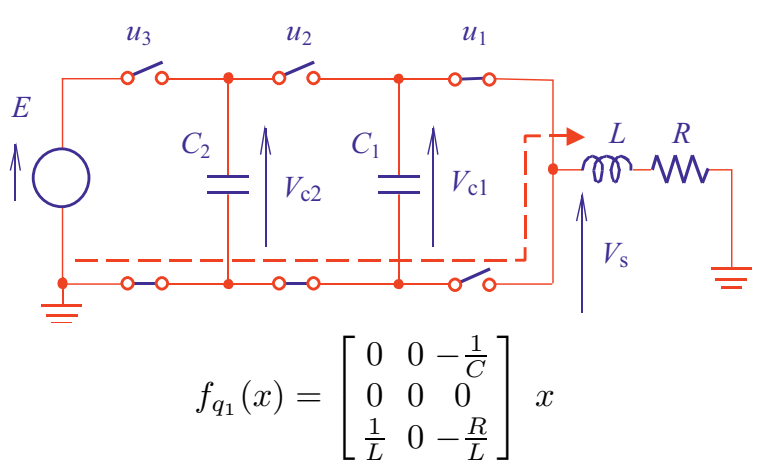

Fig. 3. Mode $q_{2},\left(u_{3}=0, u_{2}=0, u_{1}=1\right)$

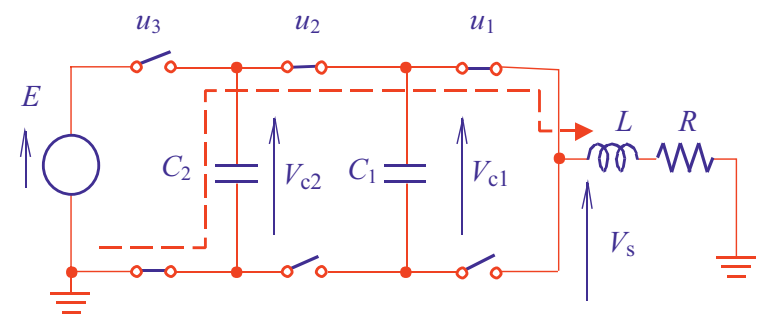

$$
f_{q_{1}}(x)=\left[\begin{array}{ccc}
0 & 0 & 0 \\
0 & 0 & -1 / C_{2} \\
0 & 1 / L & -R / L
\end{array}\right] x
$$

Fig. 5. Mode $q_{2},\left(u_{3}=0, u_{2}=0, u_{1}=1\right)$

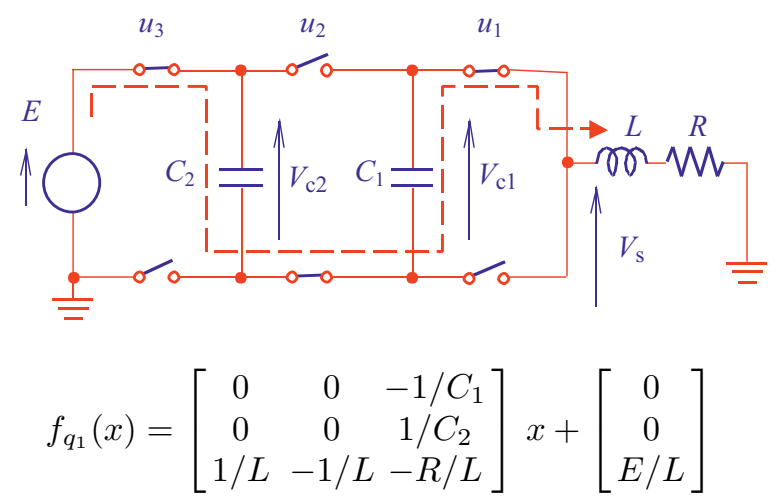

Fig. 7. Mode $q_{2},\left(u_{3}=0, u_{2}=0, u_{1}=1\right)$

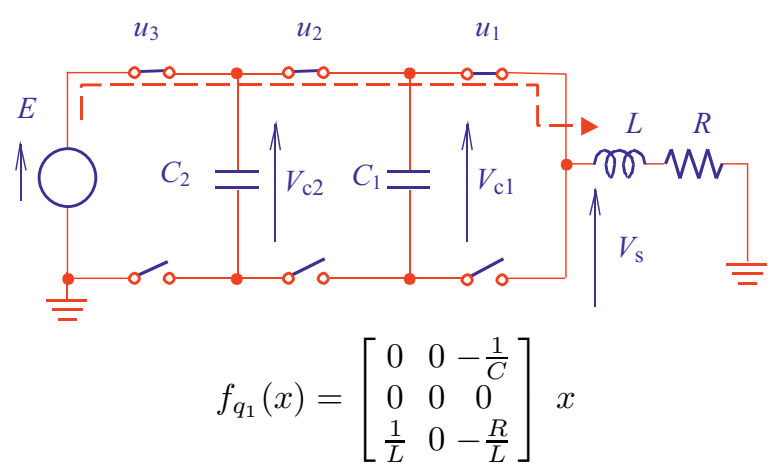

Fig. 9. Mode $q_{2},\left(u_{3}=0, u_{2}=0, u_{1}=1\right)$ 
$v_{c k}$ and load current $i$ as state variables.

$$
\begin{aligned}
\frac{\mathrm{d} v_{C 1}}{\mathrm{~d} t}= & \frac{1}{C_{1}}\left(u_{2}-u_{1}\right) i, \\
\vdots & \\
\frac{\mathrm{d} v_{C p-1}}{\mathrm{~d} t}= & \frac{1}{C_{p-1}}\left(u_{p}-u_{p-1}\right) i, \\
\frac{\mathrm{d} i}{\mathrm{~d} t}= & -\left(u_{2}-u_{1}\right) \frac{v_{C 1}}{L}-\left(u_{3}-u_{2}\right) \frac{v_{C 2}}{L}-\ldots \\
& -\left(u_{p}-u_{p-1}\right) \frac{v_{C p-i}}{L}-\frac{R}{l} i+u_{p} \frac{E}{L} .
\end{aligned}
$$

\subsection{Hybrid Automata Based Modeling and con- trol: the Three Cells Converter case}

A hybrid system is described by the interaction between a continuous dynamical system, whose behavior is described by continuous nonlinear differential equations, and by automata, with discrete event dynamics behavior $[5]$.

Hybrid systems are commonly modeled by using hybrid automata. The idea is simple: A finite "machine mode" is constructed by combining the continuous state changes, described by differential equations called modes, and the discrete state changes modeled using transitions, depending on conditions and performance of possible actions between modes [16]. Because of their nature, multicellular converters belong to the category of hybrid systems.

The hybrid system is completely described by the following $[8,9]$ :

$H=\{Q, X$, Init $, f, X q, E, G\}$ where,

- $Q=\left\{q_{1}, q_{2}, q_{3}, \ldots\right\}$ is the set of the discrete states (discrete locations);

- $X=R^{n}$ is the continuous states;

- Init $\subset Q \times X$ is a set of possible initial conditions;

- $f_{(\cdot)}(\cdot): Q \times X \rightarrow R^{n}$ is the vector field associated with each discrete state;

- $X(\cdot): Q \rightarrow P(X)$ associates an invariant field for the discrete state $q$;

- $E \subset Q \times Q$ is the set of the possible transitions in the automate;

- $G: E \rightarrow 2^{X}$ is the constraint in the continuous field for validating a transition $e \in E ; G$ is also called the guard condition;

- $R: G(e) \rightarrow P(X)$ is the relation of reinitializing the continuous variables at the time of a discrete transition.

The hybrid automata defining the operation modes of a three cell converter is shown in Fig. 2. We distinguish eight modes given by $Q=\left\{q_{1}, q_{2}, \ldots, q_{8}\right\}$ because we have three switches representing three bits. Each mode is defined in the space $X_{q i}=R^{3}, \forall q_{i} \in Q$.

The continuous dynamics for each mode is given by

$$
f_{q}(X)=A(q) X+b(q) .
$$

Where $X=\left[\begin{array}{lll}V c_{1} & V c_{2} & I\end{array}\right]^{\top}$ is the state vector of the system The hybrid control consists on choosing the suitable transitions between the different converter modes in order to achieve good performances. That is, we have to decide under what conditions the control sequence changes from one mode to another. Given the references $I_{\text {ref }}, V_{c 1 \text { ref }}$ and $V_{c 2 \text { ref }}$ and following the design approach developed in $[27,28]$, we can define the following hybrid control transitions strategy $(T(i, j)$ is the set of all $x \in R^{3}$ satisfying the property indicated below):

$$
\begin{aligned}
& T(1,2):\left[\left(V c_{1}>V c_{1 \mathrm{ref}}^{+}\right) \wedge\left(I<I_{\text {ref }}^{-}\right)\right] \\
& T(2,1):\left[\left(V c_{1}<V c_{1 \mathrm{ref}}^{+}\right) \wedge\left(I<I_{\text {ref }}^{+}\right)\right] \\
& T(1,3):\left[\left(V c_{1}<V c_{1 \mathrm{ref}}^{-}\right) \wedge\left(V c_{2}>V c_{2 \mathrm{ref}}^{+}\right) \wedge\left(I<I_{\text {ref }}^{-}\right)\right] \\
& T(3,1):\left[\left(V c_{1}>V c_{1 \mathrm{ref}}^{+}\right) \wedge\left(V c_{2}<V c_{2 \mathrm{ref}}^{-}\right) \wedge\left(I>I_{\text {ref }}^{+}\right)\right] \\
& T(1,5):\left[\left(V c_{2}<V c_{2 \text { ref }}^{-}\right) \wedge\left(I<I_{\text {ref }}^{-}\right)\right] \\
& T(5,1):\left[\left(V c_{2}>V c_{2 \mathrm{ref}}^{+}\right) \wedge\left(I>I_{\text {ref }}^{+}\right)\right] \\
& T(2,4):\left[\left(V c_{1}<V c_{1 \mathrm{ref}}^{-}\right) \wedge\left(V c_{2}>V c_{2 \mathrm{ref}}^{-}\right) \wedge\left(I<I_{\text {ref }}^{-}\right)\right] \\
& T(4,2):\left[\left(V c_{1}>V c_{1 \mathrm{ref}}^{+}\right) \wedge\left(V c_{2}<V c_{2 \mathrm{ref}}^{-}\right) \wedge\left(I>I_{\text {ref }}^{+}\right)\right] \\
& T(2,6):\left[\left(V c_{1}<V c_{1 \mathrm{ref}}^{-}\right) \wedge\left(V c_{2}<V c_{2 \mathrm{ref}}^{-}\right) \wedge\left(I<I_{\text {ref }}^{-}\right)\right] \\
& T(6,2):\left[\left(V c_{2}>V c_{2 \mathrm{ref}}^{+}\right)\right] \\
& T(3,4):\left[\left(V c_{1}>V c_{1 \mathrm{ref}}^{+}\right)\right] \\
& T(4,3):\left[\left(V c_{1}<V c_{1 \mathrm{ref}}^{-}\right) \wedge\left(V c_{2}<V c_{2 \mathrm{ref}}^{-}\right) \wedge\left(I>I_{\text {ref }}^{+}\right)\right] \\
& T(3,7):\left[\left(V c_{2}<V c_{2 \mathrm{ref}}^{-}\right)\right] \\
& T(7,3):\left[\left(V c_{1}>V c_{1 \mathrm{ref}}^{+}\right) \wedge\left(V c_{2}>V c_{2 \mathrm{ref}}^{+}\right) \wedge\left(I>I_{\text {ref }}^{+}\right)\right] \\
& T(4,8):\left[\left(V c_{2}<V c_{2 \mathrm{ref}}^{-}\right) \wedge\left(I<I_{\mathrm{ref}}^{-}\right)\right] \\
& T(8,4):\left[\left(V c_{2}>V c_{2 \mathrm{ref}}^{-}\right) \wedge\left(I>I_{\text {ref }}^{+}\right)\right] \\
& T(5,6):\left[\left(V c_{1}>V c_{1 \text { ref }}^{+}\right) \wedge\left(V c_{2}>V c_{2 \text { ref }}^{+}\right) \wedge\left(I<I_{\text {ref }}^{-}\right)\right] \\
& T(6,5):\left[\left(V c_{1}<V c_{1 \mathrm{ref}}^{-}\right)\right] \\
& T(5,7):\left[\left(V c_{1}<V c_{1 \mathrm{ref}}^{-}\right) \wedge\left(V c_{2}>V c_{2 \mathrm{ref}}^{+}\right) \wedge\left(I<I_{\mathrm{ref}}^{-}\right)\right] \\
& T(7,5):\left[\left(V c_{1}>V c_{1 \mathrm{ref}}^{+}\right) \wedge\left(V c_{2}<V c_{2 \mathrm{ref}}^{-}\right) \wedge\left(I>I_{\text {ref }}^{+}\right)\right] \\
& T(6,8):\left[\left(V c_{1}<V c_{1 \mathrm{ref}}^{-}\right) \wedge\left(V c_{2}>V c_{2 \mathrm{ref}}^{+}\right) \wedge\left(I<I_{\text {ref }}^{-}\right)\right] \\
& T(8,6):\left[\left(V c_{1}>V c_{1 \mathrm{ref}}^{+}\right) \wedge\left(V c_{2}<V c_{2 \mathrm{ref}}^{-}\right) \wedge\left(I>I_{\text {ref }}^{+}\right)\right] \\
& T(7,8):\left[\left(V c_{1}>V c_{1 \mathrm{ref}}^{+}\right) \wedge\left(I<I_{\mathrm{ref}}^{-}\right)\right] \\
& T(8,7):\left[\left(V c_{1}>V c_{1 \mathrm{ref}}^{-}\right) \wedge\left(I>I_{\text {ref }}^{+}\right)\right]
\end{aligned}
$$

The above transitions conditions have been derived in order to bring the state vector $\mathrm{X}$ inside a prescribed region around desired references

$$
X_{\text {ref }}=\left[\begin{array}{lll}
V c_{1 \text { ref }} & V c_{2 \text { ref }} & I_{\text {ref }}
\end{array}\right]^{\top} .
$$

The automaton allowing the control of the converter is shown in Fig. 10.

When a transition condition is satisfied, the system switches to another mode. The established transition conditions are given in order to ensure the regulation of voltages $\mathrm{Vc1}, \mathrm{Vc} 2$ and current I references around their reference values by creating a region where these variables evolve around. 


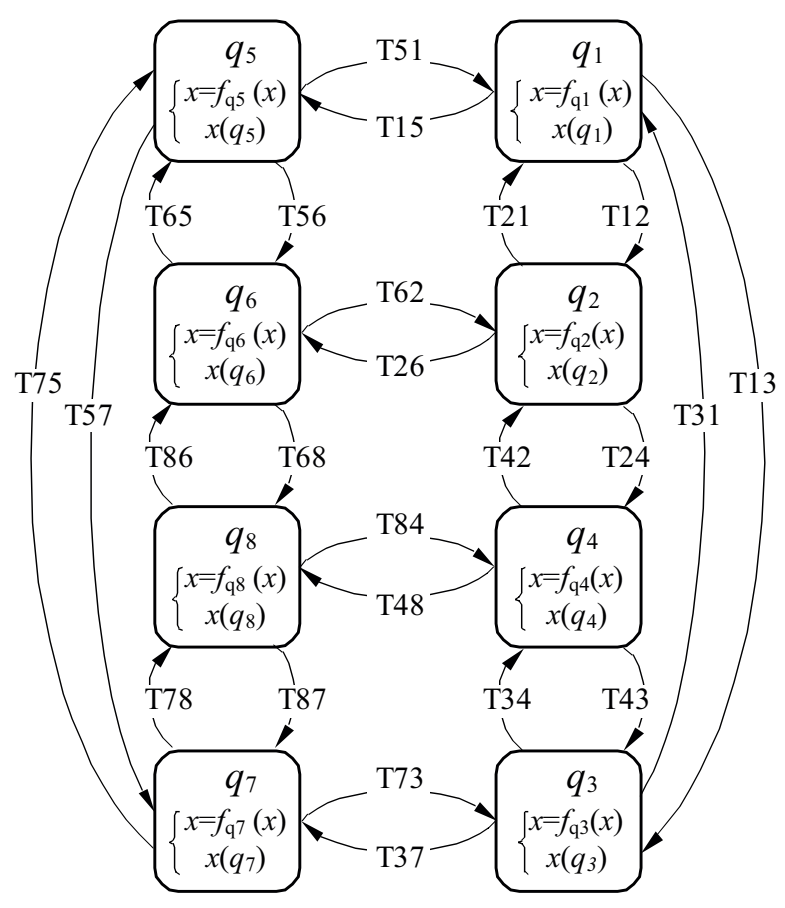

Fig. 10. Hybrid Automata Model of three Cells Converter

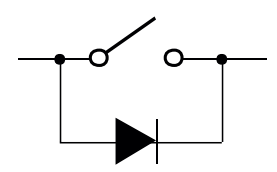

Fig. 11. High impedance fault in power transistor

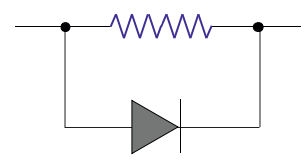

Fig. 12. Low impedance fault in power transistor

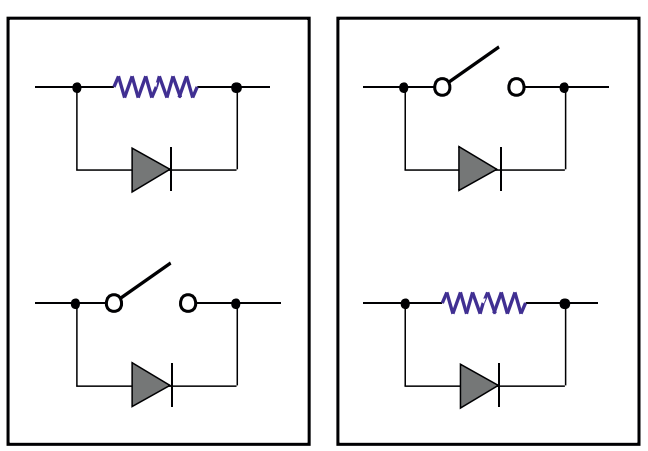

Fig. 13. Asymmetric fault in switched cell $u=0$ ou $u=1$

Control simulations have been performed with the following parameters: $L=0.5 \mathrm{mH} ; R=10 \Omega ; C 1=C 2=$ $40 \mu \mathrm{F} ; E=1500 \mathrm{~V} ; V_{c_{1 r e f}}=E / 3, V_{c_{2 r e f}}=2 E / 3$, $I_{\text {ref }}=60 \mathrm{~A} ; \varepsilon_{1}=0.02 V_{c_{1 r e f}} ; \varepsilon_{2}=0.02 V_{c_{2 r e f}} ; \Delta I=$ $0.09 I_{\text {ref }}$;

One can see that $V_{c 1}, V_{c 2}$ and $I$ converge to their references.

\section{TYPES OF FAULTS IN MULTICELLULAR CONVERTERS}

Multicellular converters as all power converters consist of active elements of semiconductors (diodes, MOSFET, IGBT, GTO) and energy storage elements (inductances and capacitors). Although studies are rare, it is common that the firsts and especially the controlled switches are the most exposed to failure. This could happen from their control as a physical fault always related to a thermal problem caused by an overload due to a power surge causing an avalanche; which provokes the increasing of internal temperature of the power interrupter [11]. We recall here some types of failure in transistors [12].

\section{1 "High impedance" fault of a transistor}

The maintaining of the open state of a transistor, due to the failure of the gate for example, results the loss of reversibility of the switch current.

\section{2 "Low impedance" fault of a transistor}

A physical failure or imperfection of controlling a transistor resulting in a state of low impedance is much more critical because the switching cell is short- circuited.

\section{3 "Asymmetric" fault}

This mode of failure results from the failure of such "low impedance" of two transistors with different levels constituting a cell where the switching cell is blocked on a fixed state $u=0$ out $u=1$.

We are interested in this work to this fault type. A cell consists of two power components, one open and one closed, which is designated by the switched control $u_{k}$. Thus, two states of fault can occur in each cell. The actuator cannot then return the control orders into an action on the system. Multiplying the actuators in the system to ensure fault tolerance is not often a good solution because of their high prices and the volume that they occupy, except for the actuators that represent a non significant percentage of the total process price, as is the case for multicellular converters where the switched interrupter represent the system actuators.

\section{RECALL ON FAULT DETECTION BASED-OBSERVER}

The methods of fault diagnosis based-observers are based on the principle of residual generation by comparing the available real state space variables of the converter with their estimated values coming from the observer. This technique is interesting because it leads to a flexible design of residues. Many studies have been developed for the observers synthesis for the diagnosis of physical systems. The diagnosis based on using of detection and isolation fault approach follows the next steps. 


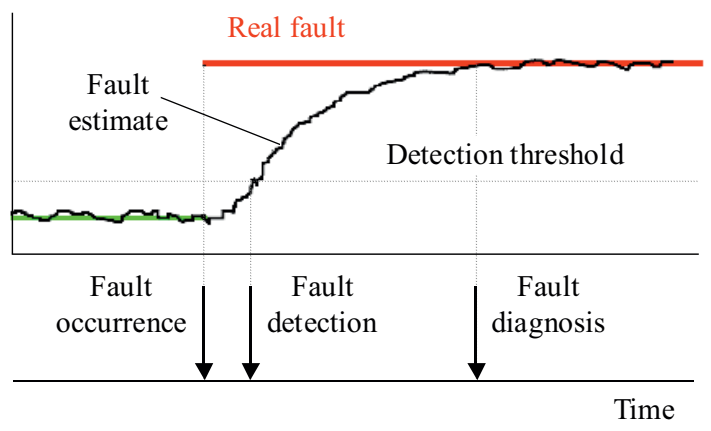

Fig. 14. Visualization of the delay in FDI proceeding [14]

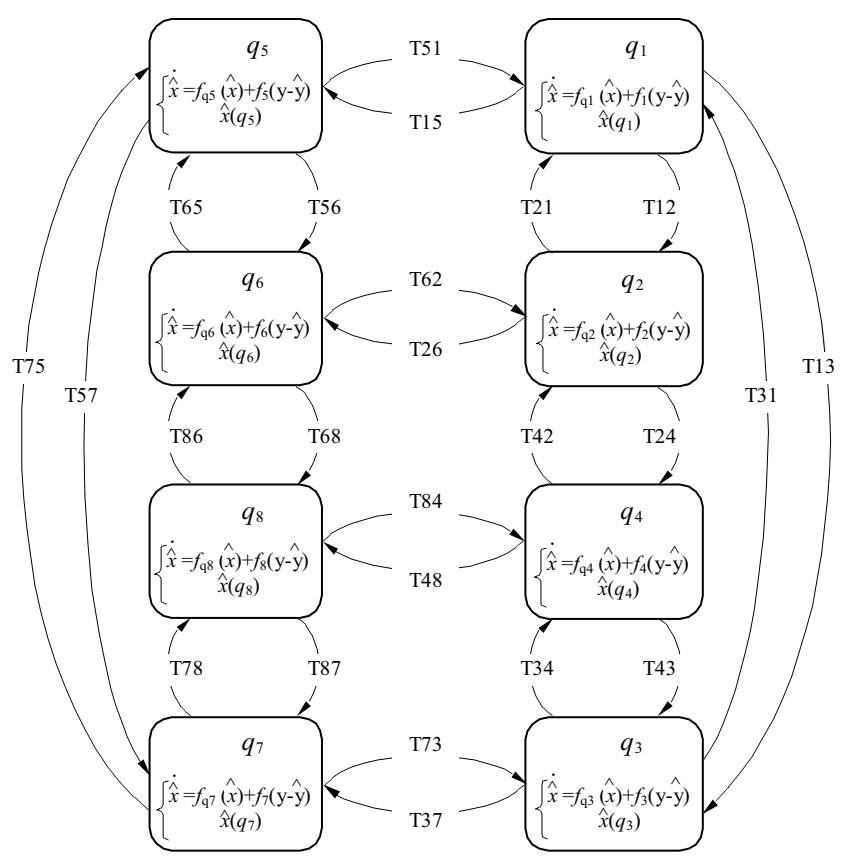

Fig. 15. Hybrid Automata Based observer of three Cells Converter

\subsection{Residual generation}

This step consists of residual generation, ie signals that can have several states that define the presence or absence of faults from the differences between the measurement of system output and its desired value.

The residual can take the following expression, $r_{i}=$ $R\left(y_{i}-\hat{y}_{i}\right)$; where $r_{i}$ denotes the $i^{\text {th }}$ residual, $R$ represents a mathematical operator (norm, average, derivative, comparison, etc), $y_{i}$ is the $i^{\text {th }}$ measured output of the system, $\hat{y}_{i}$ is the $i^{\text {th }}$ estimated output of the system. Residual are designed to be equal or converge to zero in the case of no fault and leave the origin significantly after the occurrence of a fault [13]. Therefore, it is important to obtain a structure of residual allowing a correct evaluation of it.

\subsection{Decision making}

This second step defines what is called the approach of Fault Detection and Isolation. The residual generation defines a vector of signals that provide information that can detect the fault and isolate it.
The procedure for fault detecting and isolating requires three essential steps [15]:

a) The detection. It is the step that decides whether the system is affected by a fault or not. It consists in most cases of generation of residual vector. Detection is accomplished by checking out the exceeding of thresholds by residual.

b) The isolation. This step allows locating the fault and thus determining what part of the system is affected by the anomaly.

c) Identification. The objective of this last step is to determine the causes that led to the disfunctioning in the system which can be internal (failure subsystem in part of the equipment), or external to the equipment.

\section{Evaluation of residual}

Figure 5 displays the detection process where the real fault signal changes at the instant of the fault appearing. After the fault occurring, the FDI bloc takes some time to detect the fault which is achieved by a threshold test and it requires also an additional time for the diagnosis effectiveness in order to collect all necessary inputoutput information to make a decision [14]. We note here that this level must be significant in comparison with the noise and disturbance signals. A good diagnosis should minimize the interval between the time of the fault appearing and that of the decision-making.

\section{OBSERVER DESIGN AND DIAGNOSIS OF THREE CELL CONVERTER}

In this section, the approach based on using observers to detect and isolate fault type cell is presented, and thus, by employing a hybrid observer. To generate the residuals, we begin with an apprenticeship on the dynamic behavior of the state variables of the converter. The detection of a fault is translated by a displacement of the observation error in these variables from the origin. In the other hand, to successfully isolate the fault, ie to know where exactly the fault occurs and know its condition, we have to test all possible cases of observation errors variation and then come out with a fault locator block or a residual generator.

\subsection{Synthesis of switched sliding mode observer}

Studies show that we cannot have the observability of floating voltages $V_{c 1}$ and $V_{c 2}$ at the same time of the three cell converter, so the instantaneous model is not valid to build an observer that can reconstruct the state variables of the converter.

To remedy the problem of observability, we use the compact model of the converter so that the system can be observable [16]. Therefore, we talk about a hybrid observer that does not depend only on the control inputs and the measuring output but also it depends on the state of the control that defines the modes of the system. 
Let us consider the second order interconnected affine models of the converter.

$$
\Sigma_{(i)}:\left\{\begin{array}{l}
\dot{X}_{1}(t)=A\left(q_{1}\right) X_{1}(t)+B_{1}(q, u, y)+H_{1}(q, X) \\
\dot{X}_{2}(t)=A\left(q_{2}\right) X_{2}(t)+B_{2}(q, u, y)+H_{2}(q, X) \\
y(t)=C X_{i}(t), i=1,2
\end{array}\right.
$$

where,

$$
\begin{gathered}
X_{i}=\left[\begin{array}{c}
V_{c_{i}} \\
I
\end{array}\right], A\left(q_{i}\right)=\left[\begin{array}{cc}
0 & 0 \\
-q_{i} / L & 0
\end{array}\right], \\
H_{1}(q, X)=-\frac{q_{2}}{L}\left[\begin{array}{ll}
0 & V_{c_{2}}
\end{array}\right]^{\top}, \\
H_{2}(q, X)=-\frac{q_{1}}{L}\left[\begin{array}{ll}
0 & V_{c_{1}}
\end{array}\right]^{\top}, \\
B_{1}(q, u, y)=\left[\begin{array}{c}
q_{i} \frac{1}{C_{i}} \\
\frac{R}{L} I+\frac{E}{l} u_{3}
\end{array}\right], i=1,2, \\
C=\left[\begin{array}{ll}
0 & 1
\end{array}\right], q_{1}=u_{2}-u_{1}, q_{2}=u_{3}-u_{2} .
\end{gathered}
$$

Using the general compact form of a three cell converter, we can construct the observer that takes the set of equations

$O B S$ :

$$
\begin{aligned}
\dot{\hat{X}}_{1}(t) & =A\left(q_{1}\right) \hat{X}_{1}(t)+\hat{B}_{1}(q, u, \hat{y})+H_{1}(q \hat{X})+\Phi_{1}(y-\hat{y}), \\
\dot{\hat{X}}_{2}(t) & =A\left(q_{2}\right) \hat{X}_{2}(t)+\hat{B}_{2}(q, u, \hat{y})+H_{2}(q \hat{X})+\Phi_{2}(y-\hat{y}), \\
\hat{y}(t) & =C \hat{X}_{i}(t) .
\end{aligned}
$$

where,

$$
\begin{gathered}
\hat{X}_{i}=\left[\begin{array}{c}
\hat{V} c_{i} \\
\hat{I}
\end{array}\right], A\left(q_{i}\right)=\left[\begin{array}{cc}
0 & 0 \\
-q / L & 0
\end{array}\right], \\
q_{i}=u_{i+1}-u_{i}, \quad i=1,2, \\
\hat{B}_{i}(q, u, \hat{y})=\left[\begin{array}{c}
q_{i} \frac{1}{C_{i}} \\
\frac{R}{L} \hat{I}+\frac{E}{l} u_{p}
\end{array}\right], \\
H_{i}(q, x)=\frac{1}{L}\left[\begin{array}{ll}
0 & \sum_{j=1, j \neq i}^{p-1} q_{j} \hat{V} c_{j}
\end{array}\right]^{\top} \text { and } C=\left[\begin{array}{ll}
0 & 1
\end{array}\right] .
\end{gathered}
$$

$\Phi_{i}(y-\hat{y})$ represents the gain function of the chosen observer.

For a first order sliding mode observer, the gain of observation is written as

$$
\begin{aligned}
\Phi_{i}(y-\hat{y}) & =\lambda \operatorname{sign}(S), \text { where } \lambda=\left[\begin{array}{ll}
\lambda_{1 i} & \lambda_{2 i}
\end{array}\right]^{\top}, \\
S & =(I-\hat{I}) \text { is the switching surface. }
\end{aligned}
$$

We have the following result.

Theorem. Consider system (3) represented by the automata (Fig.10) and the hybrid sliding mode observer (4) represented in automata (Fig.15). Assume that the modes $q_{i}$ are known. Then, the observation errors $e_{i}=$ $\left(X_{i}-\hat{X}_{i}\right)$ are asymptotically stable.

Pro of . From (4), one has

$$
\left\{\begin{array}{l}
\dot{\hat{V}} c_{1}=q_{1} \frac{\hat{I}}{C_{1}}+\lambda_{1} \operatorname{sign}(I-\hat{I}), \\
\dot{\hat{I}}=-\frac{R}{L} \hat{I}-q_{1} \frac{\hat{V} c_{1}}{L}+\frac{E}{l} u_{3}-q_{2} \frac{\hat{V} c_{2}}{L}+\lambda_{2} \operatorname{sign}(I-\hat{I})
\end{array}\right.
$$

and

$$
\left\{\begin{array}{l}
\dot{\hat{V}} c_{2}=q_{2} \frac{\hat{I}}{C_{2}}+\lambda_{1} \operatorname{sign}(I-\hat{I}), \\
\dot{\hat{I}}=-\frac{R}{L} \hat{I}-q_{2} \frac{\hat{V} c_{2}}{L}+\frac{E}{L} u_{3}-q_{1} \frac{\hat{V} c_{1}}{L}+\lambda_{2} \operatorname{sign}(I-\hat{I}) .
\end{array}\right.
$$

The observation errors are given by

$$
\left\{\begin{array}{c}
\dot{\tilde{V}} c_{1}=q_{1} \frac{\tilde{I}}{C_{1}}-\lambda_{11} \operatorname{sign}(I-\hat{I}) \\
\dot{\tilde{V}} c_{2}=q_{2} \frac{\tilde{I}}{C_{2}}-\lambda_{12} \operatorname{sign}(I-\hat{I}), \\
\dot{\tilde{I}}=-\frac{R}{L} \tilde{I}-q_{2} \frac{\tilde{V} c_{2}}{L}-q_{1} \frac{\tilde{V} c_{1}}{L}-\lambda_{2} \operatorname{sign}(I-\hat{I}) .
\end{array}\right.
$$

By taking $\lambda_{2}$ sufficiently large the variable $\tilde{I}=(I-\hat{I})$ converges to zero in finite time (This is the property of the sign function). On the sliding surface, $\tilde{I}=0$, one has

$$
\left[\operatorname{sign}(I-\hat{I}]_{e q u}=-q_{2} \frac{\tilde{V} c_{2}}{\lambda_{2} L}-q_{1} \frac{\tilde{V} c_{1}}{\lambda_{2} L}\right.
$$

Replacing the sign function in the first two equations we get

$$
\begin{aligned}
& \dot{\tilde{V}} c_{1}=-\lambda_{11} q_{2} \frac{\tilde{V} c_{2}}{\lambda_{2} L}-\lambda_{11} q_{1} \frac{\tilde{V} c_{1}}{\lambda_{2} L} \\
& \dot{\tilde{V}} c_{2}=-\lambda_{12} q_{2} \frac{\tilde{V} c_{2}}{\lambda_{2} L}-\lambda_{12} q_{1} \frac{\tilde{V} c_{1}}{\lambda_{2} L}
\end{aligned}
$$

Now we choose $\lambda_{11}$ and $\lambda_{12}$ such that the eigenvalues of the following matrix $A_{v c}$ are Hurwitz.

$$
A_{v c}=\left[\begin{array}{ll}
-q_{1} \lambda_{11} \frac{1}{\lambda_{2} L} & -q_{2} \lambda_{11} \frac{1}{\lambda_{2} L} \\
-q_{1} \lambda_{12} \frac{1}{\lambda_{2} L} & -q_{2} \lambda_{12} \frac{1}{\lambda_{2} L}
\end{array}\right]
$$

The dynamic of $A_{v c}$ has to be taken such that the convergence time $T<\tau_{\min }$ : the minimum time that the converter stay in a given mode (known as dwell time). Now, since the mode $q_{i}$ are known the observer automata follow the same execution as the system automata.
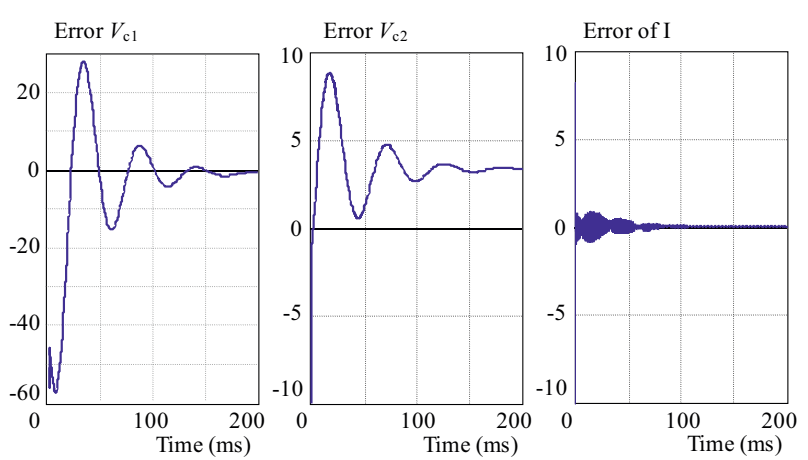

Fig. 16. State estimation errors 

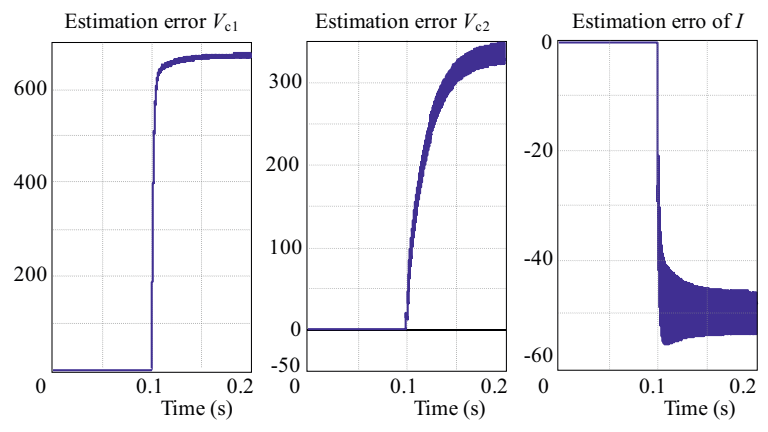

Fig. 17. Blocking of $u_{1}=0$
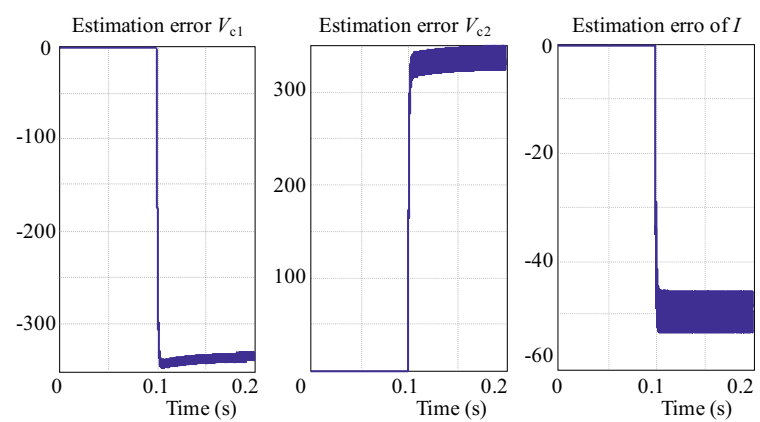

Fig. 19. Blocking of $u_{2}=0$
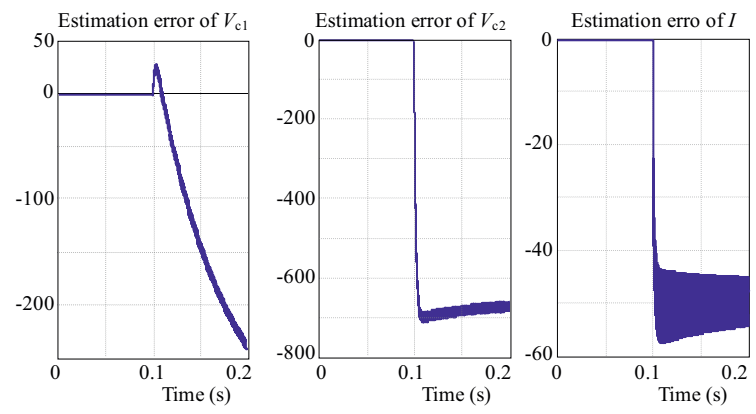

Fig. 21. Blocking of $u_{3}=0$

Figure 16 shows the estimation errors for the ideal case is considered, ie, the parameters of the converter and load are known and the measurement of the charging current is not noisy. The control is applied in open loop with DCDC functioning. The parameters of the converter and load used for simulation are as follows:

$E=1000 \mathrm{~V}, L=0.5 \mathrm{mH}, R=10 \Omega, C_{1}=C_{2}=40 \mu \mathrm{F}$, $V c_{1 r e f}=E / 3, V c_{2 r e f}=2 E / 3, I_{\text {ref }}=50 \mathrm{~A}, X_{0}=$ $[50,100,10]$.

Figure 16 shows the results of using of a sliding mode observer and illustrates the existence of oscillations in the transient state due to nonzero initial state variables of the observer. This observer is often characterized by the presence of high frequency oscillations around the equilibrium point represented by the Chattering phenomena that can be amplified by the effect of noise. These oscillations can
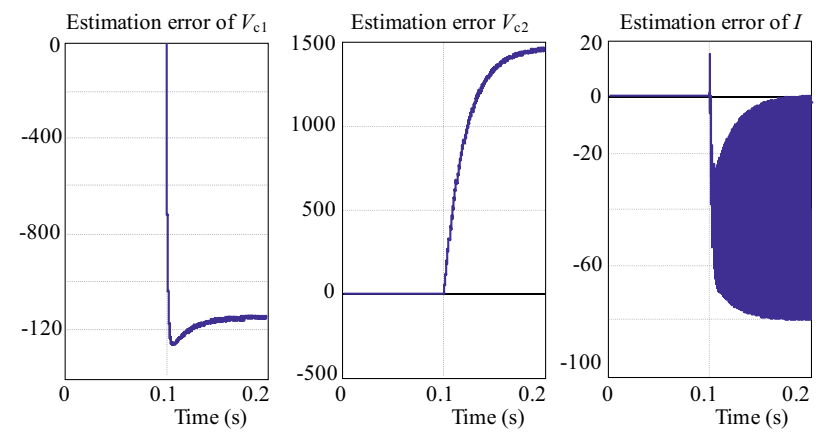

Fig. 18. Blocking of $u_{1}=1$
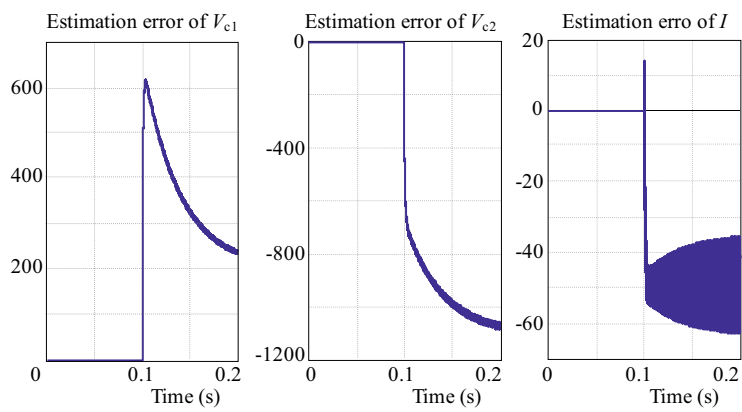

Fig. 20. Blocking of $u_{2}=1$
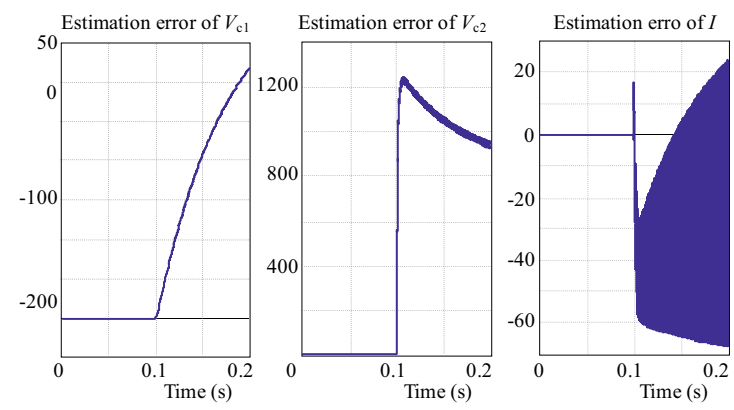

Fig. 22. Blocking of $u_{3}=1$

be reduced by reducing the value of the gain of the observer or replace the discrete function sign by a continuous function (sat or sinh) in the switching surface, in this case the performance properties of sliding mode observer are reduced.

\subsection{Learning process in presence of faults}

Learning is used to see the reaction of the continuous states of the system in presence of a fault. After testing all possible cases of faults, we get over a model of expertise in order to isolate the fault by using the dynamic behavior of each case. We use a hybrid sliding mode observer described in the previous section combined with a sliding mode type control as developed previously. We take the power source equal to $E=400 \mathrm{~V}$ and the floating voltage and load current references as $V c 1=E / 3, V c 2=2 E / 3$, 

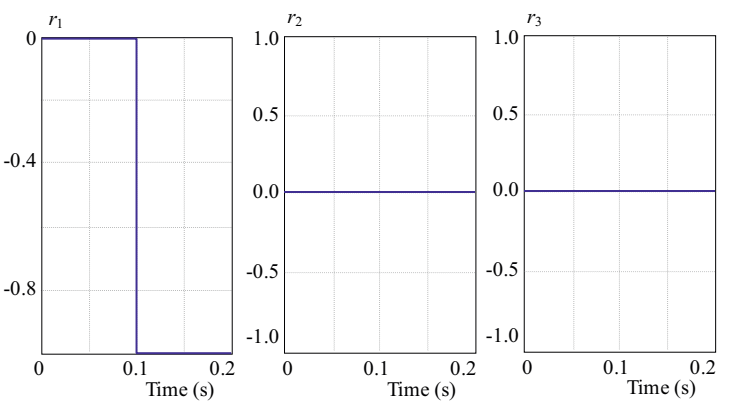

Fig. 23. Residuals for blocking of $u_{1}=0$
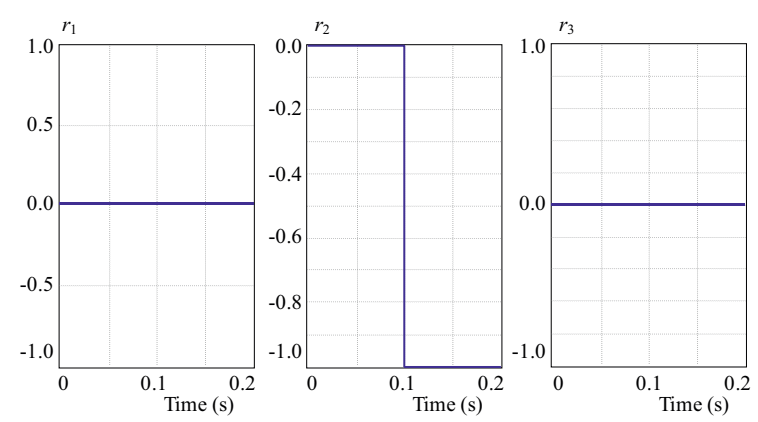

Fig. 25. Residuals for blocking of $u_{2}=0$

Table 1. Table of Signature in the presence of fault

\begin{tabular}{cccc}
\hline State & \multicolumn{3}{c}{ Evolution estimation error of } \\
\cline { 2 - 4 } fault & $V c_{1}$ & $V c_{2}$ & $V c_{3}$ \\
\hline$u_{1}=0$ & Increase & Increase & Decrease \\
$u_{1}=1$ & Decrease & Increase & Incr. then decr. \\
$u_{2}=0$ & Decrease & Increase & Decrease \\
$u_{2}=1$ & Incr. then decr. & Decrease & Incr. then decr. \\
$u_{3}=0$ & Incr. then decr. & Decrease & Decrease \\
$u_{3}=1$ & Increase & Increase & Incr. then decr. \\
\hline
\end{tabular}

Table 2. Allocation of residuals

\begin{tabular}{ccccc}
\hline$r_{3}$ & $r_{2}$ & $r_{1}$ & Blocked switch \\
\hline 0 & 0 & 0 & No Fault \\
0 & 0 & -1 & $u_{1}$ blocked in opening \\
0 & 0 & 1 & $u_{1}$ blocked in closing \\
0 & -1 & 0 & $u_{2}$ blocked in opening \\
0 & 1 & 0 & $u_{2}$ blocked in closing \\
-1 & 0 & 0 & $u_{3}$ blocked in opening \\
1 & 0 & 0 & $u_{3}$ blocked in closing \\
\hline
\end{tabular}

$I=10 \mathrm{~A}$. It is assumed throughout this study that there is one and only one fault occurs at a time because the production of more than a fault at the same time is rarely possible. The following figures show the estimation errors of the state space variables. Faults are introduced at time $t=0.1 \mathrm{sec}$.

The results can be summarized in the signature table that describes the consequences of the introduction of fault in order to model the residuals vector.
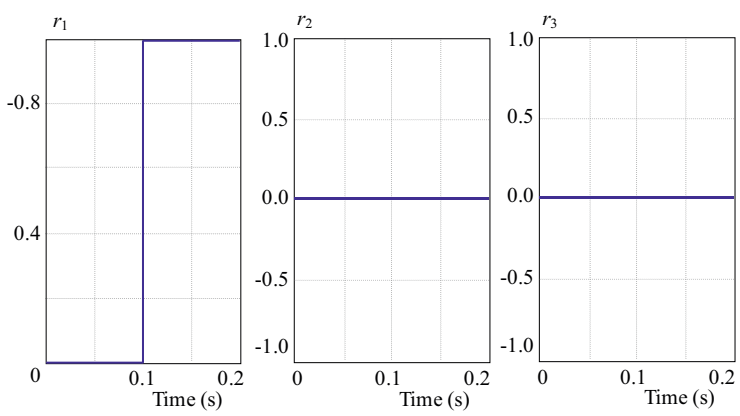

Fig. 24. Residuals for blocking of $u_{1}=1$
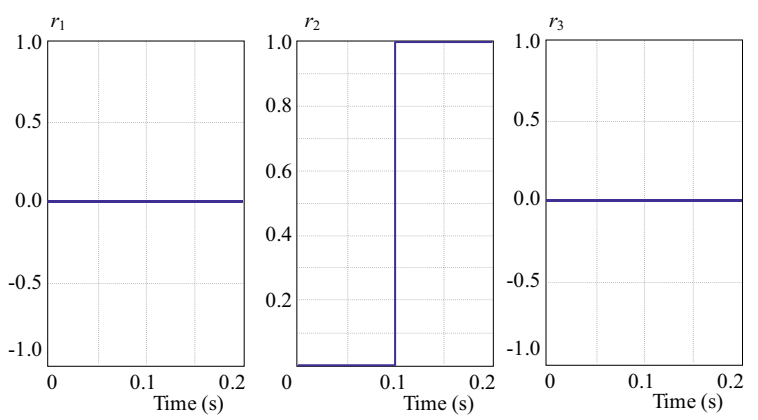

Fig. 26. Residuals for blocking of $u_{2}=1$

From the figures above and Table 1, it is apparent that the generation of a fault causes a change in the dynamic of state variables of the converter and therefore those of estimation errors. A simple comparison test between the estimation errors and predefined thresholds provides information on the presence or not of a fault. Now, to isolate the fault, i.e to know exactly the place of fault production and its nature (switch locked in closing or opening), we rely on information from the previous table signature knowing that the ultimate goal of diagnosis is to use it in the tolerant control (FTC), so the diagnostic procedure should be fast.

It can be observed from the signatures that the floating voltages dynamics are the same for many fault cases. For example, the faults $u_{1}=0$ and $u_{3}=1$ cause the two ones the increasing of floating voltages errors $\left(V_{c 1}\right.$ and $\left.V_{c 2}\right)$, to make the right decision and differentiate both from each other, we see that the dynamics of the estimation error of load current of the two cases are different. In the case $u_{1}=0$ the current decreases as the current for $u_{3}=1$ increases and then decreases. So we would use the increasing in load current for fault isolation.

\subsection{Residual generation and evaluation}

We define the estimation errors of the floating voltages and the charging current as indicators for residuals.

$$
\begin{aligned}
& r_{1}=e_{1}=V c_{1}-\hat{V} c_{1}, \\
& r_{2}=e_{2}=V c_{2}-\hat{V} c_{2}, \\
& r_{3}=e_{3}=I-\hat{I} .
\end{aligned}
$$




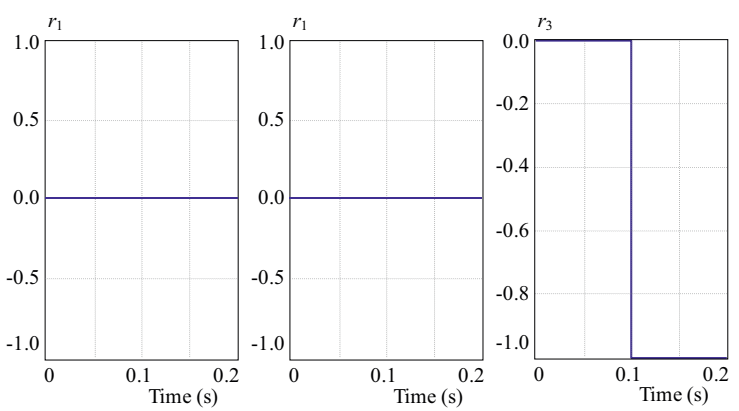

Fig. 27. Residuals for blocking of $u_{3}=0$

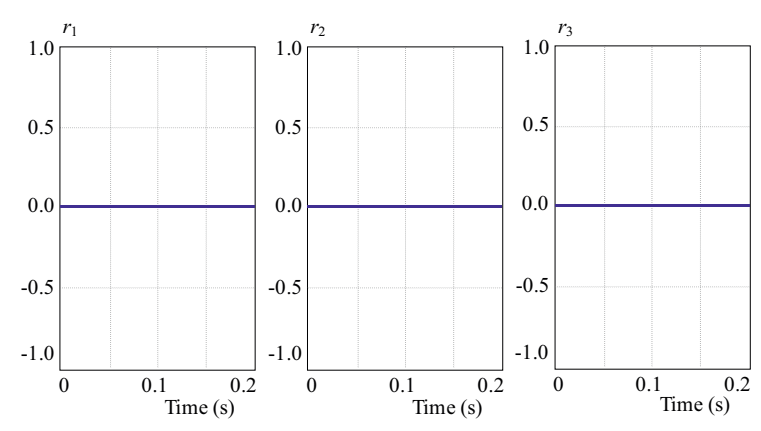

Fig. 29. Residuals for no fault

Therefore, three residuals associated with each switch are defined, $r_{i}$ with $i=1,3$. These residuals are generated by a threshold test of estimation errors and can take three states $0,-1$ or 1 . State 0 to indicate that there is no fault, the state -1 for fault in switch blocked in opening $\left(u_{i}=0\right)$ and state 1 for fault in switch blocked in closing $\left(u_{i}-1\right)$. Table 2 summarizes the allocations of each switch residual.

The simulations show that the generated residuals states are coincided exactly with the generated faults states with a very short setting time; which validates the chosen decision rules. If a comparison is made between the various tests, we can see that there are residuals faster than others. This is the case, for example, for the residuals $u_{3}=0$ and $u_{3}=1$. This is justified by the fact that the floating voltages and charging current dynamics are different in terms of increasing and decreasing. So we can say that where there is no fault, the residuals are zero and in the presence of a fault, the residuals evolve accordingly with the table of signatures. Therefore, we can come to the conclusion that the fault detection and isolation can be achieved by using a threshold of state estimation errors.

\section{CONCLUSION}

In this work, we have applied the diagnosis technique based on sliding mode hybrid observer approach, on the multicellular conversion structure. The principle is based on residuals generation that have the function to detect
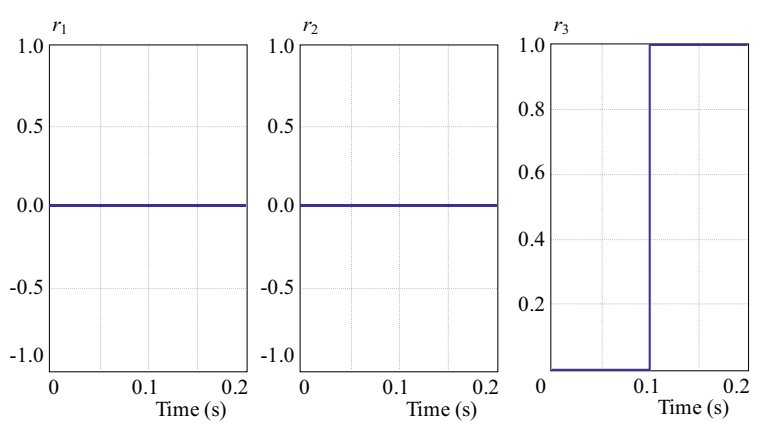

Fig. 28. Residuals for blocking of $u_{3}=1$

the cell from which the fault occurred, and know the nature of this fault, whether is locked in opening or closing. For that, we have used a hybrid observer that acts as a witness of the presence or not of a fault. Normal functioning (no fault) is characterized by the concordance of the converter state variables with those of the observer. The presence of a fault is translated by the deviation of these variables from those in the observer. This change of dynamics is used to detect and isolate the fault; which serves us in the next works dedicated for the synthesis of a fault tolerant control. Simulation results have shown the effectiveness of the proposed approach.

\section{REFERENCES}

[1] LEZANA, P.-AGUILERA, R.-RODRIGUEZ, J. : Fault Detection on Multicell Converter Based on Output Voltage Frequency Analysis, Industrial Electronics, IEEE Transactions on 56 No. 6 (2009), 2275-2283, DOI 10.1109/TIE.2009.2013845.

[2] HOSSEINI, S. H.-SADIG, A. K.-SHARIFI, A. : Estimation of Flying Capacitors Voltages in Multicell Converters, Electrical Engineering/Electronics, Computer, Telecommunications and Information Technology, 2009. ECTI-CON 2009. 6th International Conference on, vol. 01, DOI 10.1109/ECTICON.2009.5136976.

[3] STALA, R.-PIROG, S.-BASZYNSKI, M.-MONDZIK, A. PENCZEK, A.-CZEKONSKI, J.-GASIOREK, S. : Results of Investigation of Multicell Converters with Balancing Circuit, Part I, Industrial Electronics, IEEE Transactions on 56 No. 7 (2009), 2610-2619.

[4] HAGAR, A.: Generalized Multi-Cell Voltage Sourced Converter, Power Electronics and Applications, 2009. EPE '09. 13th European Conference on, 2009, pp. 1-6.

[5] DARGAHI, V.-ABARZADEH, M.-DARVISHI, A.-SALEHIFAR, M.-SHOULAIE, A.: Voltage Compensation by a Modified Mixed Cascade Flying Capacitor Multicell Inverter, Power Quality Conference (PQC), 2010, pp. 1.

[6] SADIGH, A. K.-HOSSEINI, S. H.-SABAHI, M.-GHAREHPETIAN, G. B.: Double Flying Capacitor Multicell Converter Based on Modified Phase-Shifted Pulsewidth Modulation, Power Electronics, IEEE Transactions on 25 No. 6 (2010), 1517-1526.

[7] LEZANA, P.-ACEITON, R.: Hybrid Multicell Converter Topology and Modulation, Industrial Electronics, IEEE Transactions on PP No. 99 (2010), 1.

[8] GHANES, M.-BEJARANO, F.-BARBOT, J. P. : On Sliding Mode and Adaptive Observers Design for Multicell Converter, American Control Conference, ACC'09, 2009, pp. 2134-2139.

[9] HOSSEINI, S. H.-KHOSHKBAR SADIGH, A.-SABAHI, M. : New Configuration of Stacked Multicell Converter with Reduced 
Number of dc Voltage Sources, Power Electronics, Machines and Drives (PEMD 2010), 5th IET International Conference on, 2010, pp. 1-6.

[10] BETHOUX, O.: Commande et détection de défaillance déun convertisseur multicellulaire série, $\mathrm{PhD}$ thesis, Ecole Doctorale Science Et Ingnierie de l'Universit de Cergy-Pontoise, 2005.

[11] MAVIER, J.: Convertisseurs génériques a tolérance de panne Applications pour le domaine aéronautique, $\mathrm{PhD}$ thesis, Institut Nationale Polytechnique de Toulouse, 2007.

[12] FRAGKOULIS, D.: Détection et localisation des défauts provenant des actionneurs et des capteurs: application sur un systeme non linéaire, PhD thesis, Université de Toulouse, 2008.

[13] STOYAN, K. : Robust Fault-Tolerant Control, Technical University of Delft, 2006.

[14] LOOTSMA, T. F. : Observer-Based Fault Detection and Isolation for Nonlinear Systems, PhD thesis, Department of Control Engineering, Aalborg University, Denmark, 2001.

[15] BENMANSOUR, K. Réalisation d'un banc d'essai pour la Commande et l'Observation des Convertisseurs Multicellulaires Série: Approche Hybride: PhD thesis, Université de Cergy Pontoise, 2009.

[16] BENSAID, R. Observateurs des tensions aux bornes des capacités flottantes pour les convertisseurs multicellulaires séries: PhD Thesis, Institut National Polytechnique de Toulouse 2001.

[17] GHANES, M.: Observateur adaptive pour un convertisseur multicellulaire série, Journée Inter GDR CE2/Obs-Diag-Com , Paris, 2008.

[18] HONGGANG SHENG-FEI WANG-TIPTON, C. W. : A Fault Detection and Protection Scheme for Three-Level DC-DC Converters Based on Monitoring Flying Capacitor Voltage, Power Electronics, IEEE Transactions on 27 No. 2 (2012).

[19] KHWAN-ON, S.-de LILLO, L.-EMPRINGHAM, L. WHEELER, P.: Fault-Tolerant Matrix Converter Motor Drives With Fault Detection of Open Switch Faults, Industrial Electronics, IEEE Transactions on $\mathbf{5 9}$ No. 1 (2012).

[20] WON-SANG IM-JANG-MOK KIM-DONG-CHOON LEEKYO-BEUM LEE: Diagnosis and Fault-Tolerant Control of 3-Phase AC-DC PWM Converter System, Energy Conversion Congress and Exposition (ECCE), IEEE, 2011.

[21] NGUYEN-DUY, K.-TIAN-HUA LIU-DER-FA CHEN HUNG, J. Y.: Improvement of Matrix Converter Drive Reliability by Online Fault Detection and a Fault-Tolerant Switching Strategy, Industrial Electronics, IEEE Transactions on 59 No. 1 (2012).

[22] FAZIO, P.-MARAGLIANO, G.-MARCHESONI, M.-PARODI, G. : A New Fault Detection Method for NPC Converters inbook Power Electronics and Applications (EPE 2011), Proceedings of the 14th European Conference on.

[23] ALAVI, M.-MING LUO-DANWEI WANG-DANHONG ZHANG: Fault Diagnosis for Power Electronic Inverters: A Model-Based Approach, Diagnostics for Electric Machines, Power Electronics \& Drives (SDEMPED), 2011 IEEE International Symposium on.

[24] AMGHAR, B.-DARCHERIF, M.-BARBOT, J.-P. : Observability Analysis for Parallel Multi-Cell Chopper, Systems, Signals and Devices (SSD), 8th International Multi-Conference on, 2011.

[25] TEEL, A. R. : Observer-Based Hybrid Feedback: a Local Separation Principle, American Control Conference (ACC), 2010, pp. 898-903, IEEE conferences.

[26] VAN GORP, J.-DEFOORT, M.—DJEMAI, M. : Binary Signals Design to Control a Power Converter, 50th IEEE Conference on Decision and Control and European Control Conference (CDC-ECC) Orlando, FL, USA, Dec 12-15, 2011.
[27] BENMANSOUR, K.-BENALIA, A.-DJEMAI, M.- de LEON, J. : Hybrid Control of a Multicellular Converter, Nonlinear Analysis: Hybrid Systems 1 No. 1 (March 2007), 16-19.

28] BENZINEB, O.-TAIBI, F.-BENBOUZID, M. E. H.-BOUCHERIT, M. S.-TADJINE, M. : Multicell Converters Hybrid Sliding Mode Control, International Review of Modeling and Simulation 4 No. 3 (2011).

Received 28 July 2012

Omar Benzineb was born in, Algeris, Algerie, in 1955. He received the BSc degree from the Ecole Nationale Polytechnique, Algiers, Algeria, in 1982, and the MSc degree in Electrical Engineering from the University of Blida, Blida, Algeria, in 2004. In 1995, he joined the University of Blida, Blida, Algeria as a Teaching Assistant. His research interests are in fault detection and fault-tolerant control of electric power converters and machine drives.

Fateh Taibi was born in Algiers, Algeria, in 1985. He received the BSc and MSc degrees in electrical and computer engineering from the Ecole Nationale Polytechnique, Algiers, Algeria, in 2008 and 2011, respectively. He is currently pursuing $\mathrm{PhD}$ studies on multicell converters in wind energy application.

Taous Meriem Laleg-Kirat received her engineering degree in automatic control from the National Polytechnic School of Algiers (ENP), Algeria, in June 2004. She received the Doctorate degree in applied mathematics from the French National Institute for Research in Computer Science and Control Systems (INRIA), France in October 2008. Then She joined INRIA Bordeaux in October 2008 as a post doctoral fellow first then, since september 2009 as a research fellow. In January 2011, she joined King Abdullah University of Science and Technology (KAUST), for a position of assistant professor in applied mathematics in the division of Computer, Electrical and Mathematical Sciences and Engineering (CEMSE). Her research interest is in modeling, identification, analysis and control of some complex systems with a focus on physiological systems (brain and Cardiovascular systems).

Mohamed Seghir Boucherit was born in Algiers, Algeria, in 1954. He received the $\mathrm{BSc}$, the $\mathrm{MSc}$ and $\mathrm{PhD}$ degrees all in electrical engineering from the Ecole Nationale Suprieure, Algiers, Algeria, in 1980, 1988 and 1995, respectively. Upon graduation, he joined the Electrical Engineering Department of Ecole Nationale Polytechnique where he is Professor of electrical engineering. His research interests are in the area of electrical drives and process control.

Mohamed Tadjine was born in Algiers, Algeria, in 1966. He received the Engineering degree from the Ecole Nationale Polytechnique, Algiers, Algeria, in 1990, the MSc and PhD degrees in automatic control from the National Polytechnic Institute of Grenoble, Grenoble, France, in 1991 and 1994, respectively. From 1995 to 1997, he was a Researcher at the University of Picardie, Amiens, France. Since 1997, he is with the Department of Automatic Control of the Ecole Nationale Polytechnique, Algiers, Algeria, where he is currently a Professor. His research interests are in robust and nonlinear control. 